\title{
PERAMBATAN GELOMBANG OPTIK PADA GRATING SINUSOIDAL DENGAN CHIRP DAN TAPER
}

\author{
Isnani Darti \\ Jurusan Matematika, Fakultas MIPA \\ Universitas Brawijaya, Jl. Veteran Malang 65145 \\ email: isnanidarti@yahoo.com
}

\begin{abstract}
Abstrak
Artikel ini membahas model perambatan gelombang optik pada grating sinusoidal takhomogen. Model tersebut diturunkan dengan mereduksi secara eksak persamaan Helmholtz menjadi sistem persamaan diferensial orde satu dengan syarat awal yang dapat diselesaikan dengan metode Runge-Kutta orde empat. Metode ini disebut Metode Integrasi Langsung (MIL). Formulasi MIL sangat sederhana baik dalam hal penurunannya maupun implementasinya karena tidak memerlukan prosedur iterasi maupun optimasi. Dengan menggunakan MIL, dipelajari perubahan respon optik pada grating sinusoidal akibat variasi amplitudo modulasi indeks (taper) dan variasi frekuensi spasial grating (chirp). Hasil simulasi menunjukkan bahwa taper menyebabkan adanya fenomena penghilangan side-lobe pada spektrum transmitansi. Adanya chirp menyebabkan penghalusan side-lobe pada spektrum transmitansi dengan semakin besar parameter chirp menyebabkan peningkatan transmitansi di sekitar pusat band-gap dari grating homogen. Selain implementasi integrasi numerik (Runge-Kutta), MIL merupakan metode eksak sehingga dapat digunakan untuk mengevaluasi validitas metode yang sering digunakan yaitu Persamaan Moda Tergandeng (PMT). Dari hasil perbandingan dapat disimpulkan bahwa secara umum PMT kurang akurat dalam menganalisis struktur grating sinusoidal baik homogen maupun tak-homogen.
\end{abstract}

Kata kunci: grating sinusoidal tak-homogen (taper, chirp), metode integrasi langsung, persamaan moda tergandeng, metode Runge-Kutta orde empat.

\section{Pendahuluan}

Salah satu blok komponen penting dalam peralatan optik terpadu adalah struktur grating, yaitu suatu sistem yang terbuat dari beberapa lapisan medium dielektrik yang disusun secara bergantian (periodik). Struktur ini memiliki sifat dasar bahwa gelombang dengan frekuensi yang termasuk dalam suatu interval tertentu akan dipantulkan secara sempurna oleh struktur grating. Interval frekuensi ini disebut dengan band gap; lihat (Joannopoulos et al. 1995, Soukoulis 1993, Soukoulis 1996). Salah satu struktur grating yang sering dikaji adalah grating dengan indeks bias berbentuk sinusoidal (disebut grating sinusoidal). Struktur grating tersebut telah diaplikasikan dalam berbagai peralatan optik yang menarik seperti filter (Lei et al. 1997), cermin sempurna (Joannopoulos et al. 1995), optical limiter dan switching (Scalora et al., 1994, Tran, 1997) dan sensor (Mandal et al., 2005).

Sebelum mendesain peralatan yang menggunakan struktur grating, adalah sangat penting untuk mengetahui perilaku transmisi gelombang optik yang melewati struktur tersebut. Untuk mempelajari perilaku transmisi secara eksperimen dibutuhkan fasilitas yang sangat mahal seperti "clean room". Oleh karena itu pengertian secara teoritis dan prinsip-prinsip dasar sangat diperlukan untuk efisiensi waktu dan biaya. Untuk itu perlu dikembangkan metode analisis yang sangat akurat dan efisien sebagai dasar untuk simulasi komputer. Metode yang sering banyak diaplikasikan untuk mempelajari fenomena pada grating sinusoidal adalah Persamaan Moda Tergandeng (PMT) (De Sterke at at., 1991). Secara umum PMT dikembangkan dengan mengasumsikan bahwa amplitudo gelombang bervariasi secara lambat (Slowly Varying Envelope 
Approximation, disingkat SVEA) sehingga untuk kasus-kasus tertentu keakuratannya diragukan. Untuk mengatasi hal tersebut, Suryanto dan Darti (2005) telah mengembangkan Metode Integrasi Langsung (MIL). Dalam metode ini, persamaan Maxwell diselesaikan dalam domain frekuensi dan ditransformasikan ke dalam sistem persamaan diferensial yang dapat diintegrasikan secara langsung. Metode tersebut telah diaplikasikan untuk mempelajari respon optik baik dari grating step-index dengan beberapa lapisan cacat (Suryanto dan Darti, 2005; Suryanto, 2006) maupun grating sinusoidal dengan pergeseran fasa (Suryanto dan Darti, 2008; Suryanto, 2009). Dalam artikel ini Metode Integrasi Langsung akan diaplikasikan untuk mempelajari perubahan respon optik pada grating sinusoidal akibat variasi amplitudo modulasi indeks (taper) dan variasi frekuensi spasial (chirp).

\section{Grating Sinusoidal Tak-Homogen dan Metode Numerik}

Struktur grating sinusoidal yang akan dikaji dalam artikel ini adalah struktur grating dengan indeks bias berbentuk

$$
n(z)=n_{0}+\delta(z) \sin \left(\frac{2 \pi}{\Lambda(z)} z\right)
$$

dengan $n_{0}, \delta(z)$ dan $\Lambda(z)$ masing-masing adalah rata-rata indeks bias medium, kedalaman modulasi indeks sinusoidal dan panjang periode grating. Secara skematik, struktur grating yang dikaji dapat dilihat pada Gambar 1.

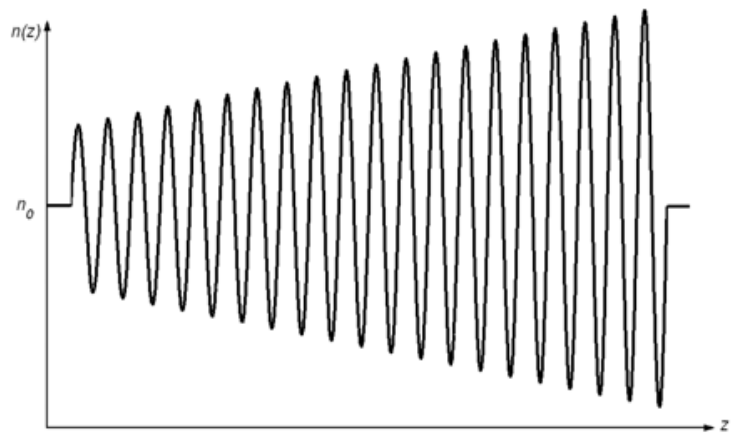

GAMBAR 1. Gambar skematik variasi indeks grating terhadap $z$.

\subsection{Persamaan Gelombang dan Metode Integrasi Langsung}

Perambatan gelombang elektromagnetik secara umum dimodelkan oleh persamaan Maxwell. Pada medium linear satu dimensi, persamaan Maxwell direduksi menjadi persamaan Helmholtz (Suryanto et al., 2003a, Suryanto et al., 2003b):

$$
\frac{d^{2} E}{d z^{2}}+k^{2} n(z)^{2} E=0
$$

dimana $E$ adalah gelombang elektrik, $k=\omega / c$ adalah konstanta propagasi di ruang hampa dengan $c$ adalah kecepatan cahaya. Persamaan (2) dapat dinyatakan dalam bentuk sistem persamaan diferensial:

$$
\begin{aligned}
& \frac{d E(z)}{d z}=V(z) \\
& \frac{d V(z)}{d z}=-k^{2} n(z)^{2} E(z) .
\end{aligned}
$$

Perhatikan bahwa sistem persamaan (3) diturunkan dari persamaan Helmholtz (2) tanpa melakukan aproksimasi. Untuk menyelesaikan persamaan (3), diperlukan syarat awal. Syarat awal ditentukan dengan mengasumsikan bahwa gelombang elektromagnetik dengan frekuensi $\omega$ dan amplitudo $A_{d t g}$ diiluminasikan dengan sudut normal hanya dari 
sebelah kiri grating. Secara umum, gelombang datang tersebut akan dipantulkan (misalkan gelombang pantul mempunyai amplitudo $A_{p t l}$ ) oleh struktur grating dan sebagian diteruskan oleh grating (misal dengan amplitudo $A_{t r}$ ). Jika grating diasumsikan terletak di antara $z=0$ dan $z=z_{\text {max }}$ dan medium di luar grating mempunyai indeks bias konstan $n=n_{0}$, maka medan elektrik di luar grating secara umum adalah

$$
\begin{aligned}
& E(z)=A_{d t g} e^{-i k n_{0} z}+A_{p t l} e^{i k n_{0} z} ; z \leq 0 \\
& E(z)=A_{t r} e^{-i k n_{0}(z-L)} ; z \geq z_{\max } .
\end{aligned}
$$

Dengan mengimplementasikan kondisi antar-muka pada $z=0$ dan $z=z_{\max }$, didapat bahwa

$$
\begin{aligned}
& E(L)=A_{t r} \\
& V(L)=-i k n_{0} A_{t r}
\end{aligned}
$$

dan amplitudo gelombang datang dan gelombang pantul ditentukan oleh

$$
\begin{aligned}
& A_{d t l}=\frac{1}{2}\left(E(0)+\frac{i}{k n_{0}} V(0)\right) \\
& A_{p t l}=\frac{1}{2}\left(E(0)-\frac{i}{k n_{0}} V(0)\right) .
\end{aligned}
$$

Penyelesaian persamaan (3) dengan kondisi awal (5) dapat dicari dengan menggunakan metode integrasi numerik mulai dari $z=z_{\max }$ sampai $z=0$. Dalam artikel ini, metode yang digunakan adalah metode Runge-Kutta orde empat. Setelah seluruh medan elektrik terhitung, amplitudo gelombang datang dan gelombang pantul dapat dihitung dengan mengaplikasikan persamaan (6) dan reflektansi dan transmitansi dapat ditentukan dengan persamaan:

$$
R=\left|\frac{A_{p t l}}{A_{d t g}}\right|^{2} \quad \text { dan } T=\left|\frac{A_{t r}}{A_{d t g}}\right|^{2} .
$$

\subsection{Persamaan Moda-Tergandeng (PMT)}

Untuk menurunkan PMT, pertama diasumsikan bahwa variasi modulasi amplitudo grating $\delta(z)$ bernilai cukup kecil, sehingga kuadrat indeks bias dalam persamaan (1) dapat diaproksimasi menjadi

$$
n(z)^{2}=n_{0}{ }^{2}+2 n_{0} \delta(z) \sin \left(\frac{2 \pi}{\Lambda(z)} z\right) .
$$

Selanjutnya, medan elektrik diasumsikan sebagai superposisi dari moda normal dari medium konstan (yaitu jika $\delta(z)=0$ ) tetapi dengan amplitudo tergantung pada posisi $z$, yaitu

$$
E(z)=A(z) \exp \left(-i k_{0} z\right)+B(z) \exp \left(i k_{0} z\right)
$$

dengan $k_{0}=k n_{0}$. Dengan mengasumsikan SVEA dan menganggap bahwa moda harmonik spasial order tiga sangat kecil, persamaan Helmholtz (2) direduksi menjadi PMT:

$$
\begin{aligned}
& \frac{\partial A}{\partial z}=\frac{1}{2} k \delta B \exp \left(i\left(2 k_{0}-K\right) z\right) \\
& \frac{\partial B}{\partial z}=\frac{1}{2} k \delta A \exp \left(-i\left(2 k_{0}-K\right) z\right)
\end{aligned}
$$


dengan $K=\frac{2 \pi}{\Lambda}$. Untuk grating homogen, penyelesaian analitik PMT dapat ditemukan dalam literatur (Yeh, 1988), yaitu:

$$
\begin{aligned}
& A(z)=\frac{s \cosh \left[s\left(z_{\text {max }}-z\right)\right]+\frac{1}{2} i \Delta k \sinh \left[s\left(z_{\text {max }}-z\right)\right]}{s \cosh \left(s z_{\text {max }}\right)+\frac{1}{2} i \Delta k \sinh \left[s z_{\text {max }}\right]} A_{0} \exp \left(\frac{1}{2} i \Delta k z\right) \\
& B(z)=-\frac{i \kappa \sinh \left[s\left(z_{\text {max }}-z\right)\right]}{s \cosh \left(s z_{\text {max }}\right)+\frac{1}{2} i \Delta k \sinh \left[s z_{\text {max }}\right]} A_{0} \exp \left(-\frac{1}{2} i \Delta k z\right)
\end{aligned}
$$

dimana $\Delta k=2 k_{0}-K, \kappa=\frac{1}{2} k \delta, s=\kappa^{2}-\left(\frac{\Delta k}{2}\right)^{2}$ and $A_{0}=A(0)$. Tetapi untuk grating tak-homogen, penyelesaian eksak relatif sulit didapatkan. Dalam artikel ini PMT pada persamaan (1) diintegralkan secara numerik seperti pada MIL, yaitu menggunakan metode Runge-Kutta order empat dengan syarat awal

$$
\begin{aligned}
& A\left(z_{\text {max }}\right)=A_{t r} \\
& B\left(z_{\text {max }}\right)=0 .
\end{aligned}
$$

Reflektansi dan transmitansi dapat ditentukan dengan cara yang identik dengan MIL, yaitu

$$
R=\left|\frac{B(0)}{A(0)}\right|^{2} \text { dan } T=\left|\frac{A\left(z_{\max }\right)}{A(0)}\right|^{2} .
$$

\section{Simulasi Numerik Perambatan Gelombang Optik pada Grating Sinusoidal}

\subsection{Grating Homogen}

Pada bagian ini akan ditunjukkan hasil simulasi numerik gelombang optik pada grating homogen. Khususnya akan dibahas sifat-sifat transmisi grating sinusoidal homogen, yaitu struktur dengan indeks bias seperti pada persamaan (1) dengan $n_{0}=2$, $\delta(z)=\delta_{0}=0.4$ dan $\Lambda(z)=\Lambda_{B}=\frac{1}{2 n_{0}}$.

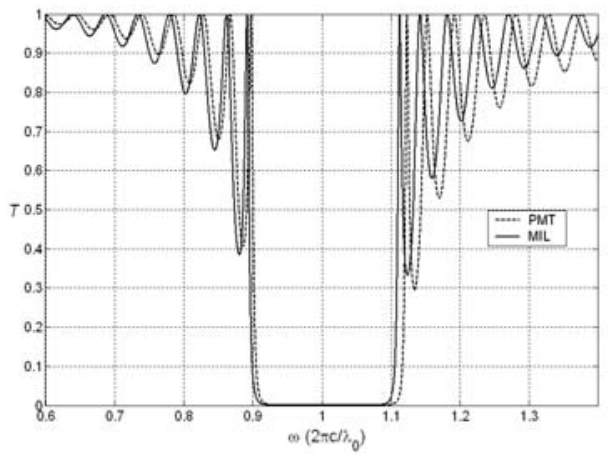

(a)

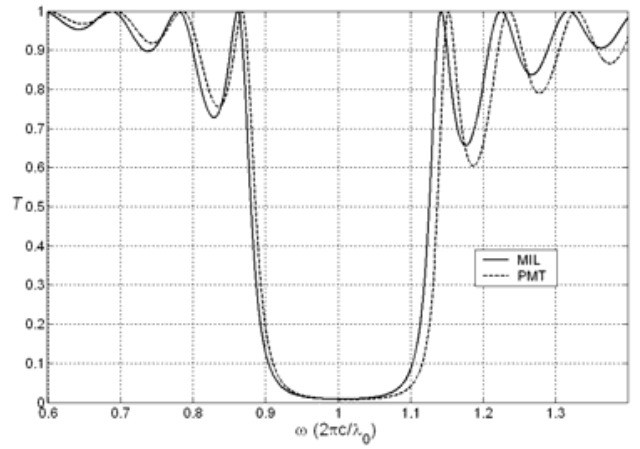

(b)

GAMBAR 2. Spektrum transmitansi grating sinusoidal homogen dengan (a) $N=10$ dan (b) $N=20$; dihitung dengan MIL dan PMT.

Pada Gambar 2 ditunjukkan pengaruh jumlah perioda grating terhadap karakteristik transmisi. Terlihat bahwa semakin banyak perioda, semakin banyak pula jumlah frekuensi resonan (frekuensi dengan transmitansi $T=1$ ) yang muncul. Terlebih 
lagi, pada ujung-ujung band-gap untuk jumlah perioda yang lebih besar, resonan memiliki lebar spektrum yang lebih sempit.

Perbandingan hasil MIL dengan PMT untuk grating sinusoidal homogen juga dapat dilihat pada Gambar 2. Secara umum PMT memberikan spektrum transmitansi dengan jumlah resonan yang sama dengan MIL tetapi dengan side-lobe lebih dangkal untuk spektrum di sebelah kiri band-gap dan lebih dalam untuk spektrum di sebelah kanan band-gap. Lebih lanjut, spektrum transmitansi hasil PMT tergeser ke kanan jika dibandingkan spektrum hasil MIL. Hasil ini menunjukkan bahwa PMT kurang akurat dalam menganalisis grating sinusoidal. Perbedaan antara spektrum hasil PMT dan MIL semakin berkurang dengan semakin kecilnya nilai $\delta_{0}$.

\subsection{Grating dengan Taper Linear}

Untuk melihat pengaruh taper, diasumsikan bahwa amplitudo modulasi indeks bias mengalami peningkatan (untuk taper positif) atau penurunan (untuk taper negatif) secara linear, yaitu grating mempunyai modulasi amplitudo secara linear:

$$
\delta n(z)=\delta_{0}(1+\Delta n z)
$$

dengan panjang perioda dan rata-rata modulasi indeks bias bernilai konstan yaitu $\Lambda(z)=\frac{1}{2 n_{0}}$ dan $\delta_{0}=0.4$.

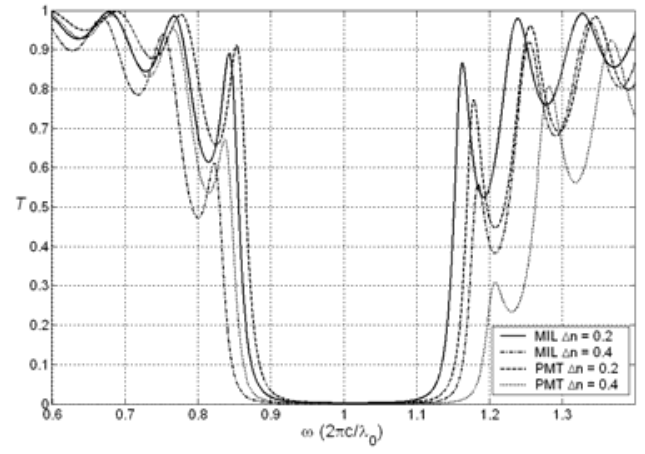

(a)

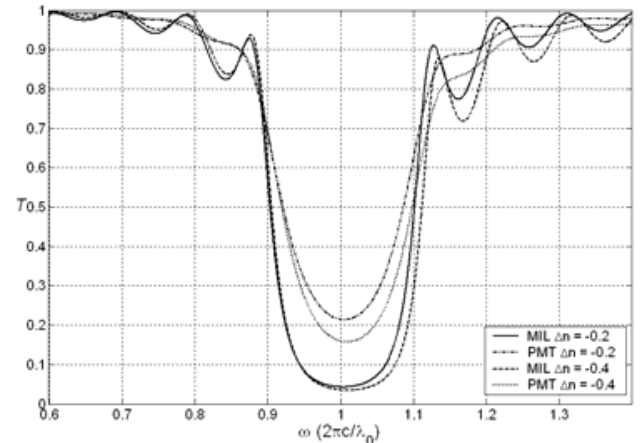

(b)

GAMBAR 3. Spektrum transmitansi grating $(N=10)$ dengan taper linear: (a) taper positif ; (b) taper negatif.

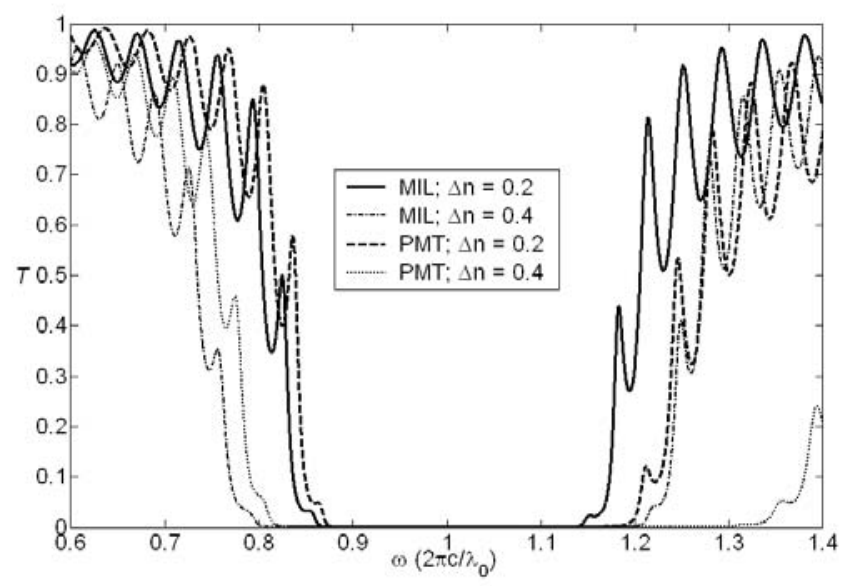

GAMBAR 4. Spektrum transmitansi grating dengan taper positif dan $N=20$.

Transmitansi dari grating dengan jumlah perioda $N=10$ dapat dilihat pada Gambar 3.a untuk taper positif dan Gambar 3.b untuk taper negatif. Adanya taper pada grating, baik positif ataupun negatif menunjukkan adanya fenomena penghilangan side-lobe. Perbedaannya, taper positif mengakibatkan interval band-gap semakin lebar dan sebaliknya taper negatif mengakibatkan penghilangan interval band-gap. Fenomena 
penghilangan side-lobe dan pelebaran/penghilangan interval band-gap semakin terlihat apabila parameter taper $\Delta n$ diperbesar atau jika jumlah perioda grating $N$ ditingkatkan. Sebagai contoh, fenomena tersebut dapat dilihat dari spektrum transmitansi grating sinusoidal dengan taper linear dan jumlah perioda $N=20$, lihat Gambar 4.

Pada Gambar 3 dan 4 juga dibandingkan spektrum transmitansi grating dengan taper hasil MIL dengan hasil PMT. Pada gambar-gambar tersebut dapat dilihat bahwa perbedaan antara hasil MIL dan PMT serupa dengan masalah grating homogen. Hasilhasil simulasi menunjukkan bahwa PMT semakin tidak akurat jika parameter taper atau jumlah perioda grating diperbesar.

\subsection{Grating dengan Chirp}

Chirp pada grating dibuat dengan mengubah periodasitas dari grating homogen, yaitu panjang perioda masing-masing grating diberikan oleh

$$
\begin{aligned}
& \Lambda_{i}=\Lambda_{\min }+\left(\frac{\Lambda_{\max }-\Lambda_{\min }}{N}\right)(i-1) ; \text { untuk chirp positif } \\
& \Lambda_{i}=\Lambda_{\max }-\left(\frac{\Lambda_{\max }-\Lambda_{\min }}{N}\right)(i-1) ; \text { untuk chirp negatif }
\end{aligned}
$$

dengan $\Lambda_{\max }=(1+\sigma) \Lambda_{B} ; \Lambda_{\min }=(1-\sigma) \Lambda_{B} ; \delta(z)=\delta_{0}=0.4$. Gambar 5 menunjukkan spektrum transmitansi dari grating dengan chirp dan jumlah perioda $N=10$. Terlihat pada gambar tersebut bahwa chirp menghaluskan side-lobe dan apabila parameter chirp diperbesar maka transmitansi meningkat di sekitar pusat band-gap dari grating homogen.

Pada Gambar 5 terlihat bahwa PMT untuk masalah grating dengan chirp sangat tidak akurat. Hal ini ditunjukkan oleh perbedaan spektrum transmitansi hasil MIL dan PMT. Hasil simulasi lain menunjukkan bahwa semakin besar parameter chirp ataupun semakin besar jumlah perioda grating menyebabkan PMT semakin tidak akurat.

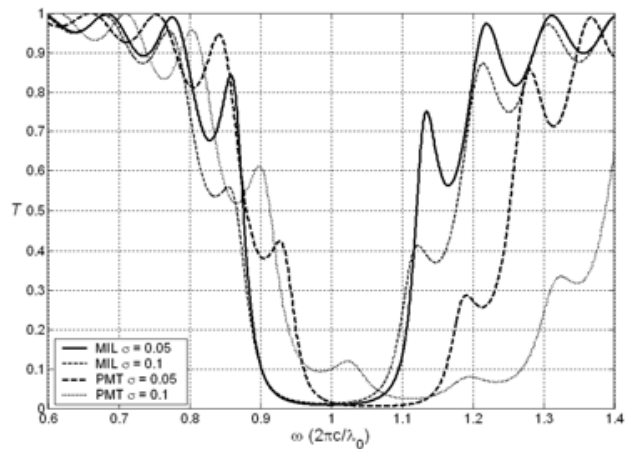

(a)

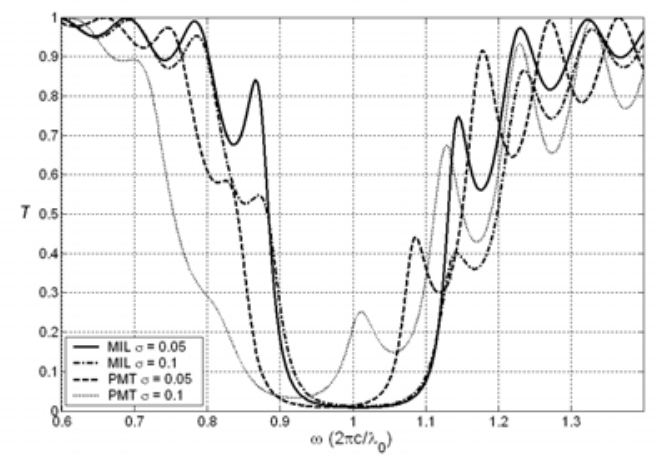

(b)

GAMBAR 5. Spektrum transmitansi grating dengan jumlah perioda $N=10$ : (a) chirp negatif dan (b) chirp positif.

\section{Kesimpulan}

Dalam artikel ini telah dikembangkan MIL untuk analisis grating sinusoidal takhomogen. Dalam metode tersebut persamaan Helmholtz secara langsung diubah menjadi sistem persamaan diferensial orde satu dengan syarat awal yang dapat diselesaikan secara langsung oleh metode Runge-Kutta order empat. Jika dibandingkan dengan MIL, PMT secara umum kurang akurat dalam menganalisis grating sinusoidal baik homogen maupun tak-homogen.

Dengan menggunakan MIL, telah dipelajari pengaruh taper dan chirp terhadap respon optik pada grating sinusoidal. Ditunjukkan juga bahwa taper dan chirp masing- 
masing menyebabkan adanya fenomena penghilangan dan penghalusan side-lobe pada spektrum transmitansi. Parameter chirp yang besar mengakibatkan peningkatan transmitansi di sekitar pusat band-gap (grating homogen).

\section{Ucapan Terima Kasih}

Artikel ini merupakan bagian dari hasil penelitian fundamental yang dibiayai oleh Direktorat Penelitian dan Pengabdian Kepada Masyarakat (DP2M) dengan Surat Perjanjian Pelaksanaan Hibah Penugasan Penelitian Desentralisasi Nomor: 320/SP2H/PP/DP2M/III/2008, Direktorat Jenderal Pendidikan Tinggi, Departemen Pendidikan Nasional. Penulis mengucapkan terima kasih kepada A. Suryanto (Jurusan Matematika, Universitas Brawijaya) atas diskusi dan saran yang sangat bermanfaat pada penulisan artikel ini.

\section{Daftar Pustaka}

De Sterke, C.M., K.R. Jackson, B.D. Robert, 1991, Nonlinear coupled-mode equations on a finite interval: a numerical procedure, J. Opt. Soc. Am. B. 8: 403.

Joannopoulos, J.D., R.D. Meade dan J.N. Winn, 1995, Photonics Crystals, Princeton University Press, Princeton, NJ.

Lei, X-Y., H. Li, F. Din, W. Zhang dan N-B. Ming, 1997, Novel application of a perturbed photonic crystal: high-quality filter, Appl. Phys. Lett. 71: 2889.

Mandal, J., Y. Shen, S. Pal, T. Sun, K.T.V. Grattan dan A.T. Augousti, 2005, Bragg grating tuned fiber laser system for measurement of wider range temperature and strain, Opt. Comm. 244: 111.

Scalora, M., J.P. Dowling, C.M. Bowden dan M.J. Bloemer,1994, Optical limiting and switching of ultrashort pulses in nonlinear photonic band gap materials, Phys. Rev. Lett. 73: 1368.

Soukoulis, C.M., 1993, Photonics Band Gaps and Localization, Plenum, New York.

Soukoulis, C.M., 1996, Photonics Band Gaps Materials, Kluwer Academic, Dordrecht.

Suryanto, A., E. van Groesen, M. Hammer dan H.J.W.M. Hoekstra, 2003a, A finite element scheme to study the nonlinear optical response of a finite grating without and with defect, Opt. and Quant. Electr. 35: 313.

Suryanto, A., E. van Groesen dan M. Hammer, 2003b, Finite element analysis of optical bistability in one-dimensional nonlinear photonics band gap structures with a defect, J. Nonl. Opt. Phys. \& Mater. 12:187.

Suryanto, A. dan I. Darti, 2005, Perubahan sifat-sifat transmisi gelombang optik pada struktur grating satu dimensi akibat adanya beberapa lapisan cacat, Laporan Penelitian Dasar DP2M-DIKTI.

Suryanto, A. 2006, Transmission characteristics of one-dimensional photonics bandgap structures with some defects, J. Nonl. Opt. Phys. \& Mater. 15: 331.

Suryanto, A. dan I. Darti, 2008, Pengaruh variasi frekuensi spatial dan pergeseran fasa terhadap karakteristik optical bistability pada fiber Bragg grating nonlinear berstruktur sinusoidal, Laporan Penelitian Fundamental DP2M-DIKTI.

Suryanto, A., 2009, On the Numerical Modelling of optical switching in nonlinear phase-shifted grating, J. Nonl. Opt. Phys. \& Mater. 18: 129.

Tran, P., 1997, Optical limiting and switching of short pulses by use of a nonlinear photonic bandgap structure with a defect, J. Opt. Soc. Am. B14: 2589.

Yeh, P., 1988, Optical waves in layered media, John Wiley \& Sons, New York. 